Portland State University

PDXScholar

\title{
Performance of US Concrete Highway Bridge Decks Characterized by Random Parameters Binary Logistic Regression
}

\author{
Omar Ghonima \\ University of Delaware \\ Jason C. Anderson \\ Portland State University, jason.c.anderson@pdx.edu \\ Thomas Schumacher \\ Portland State University, thomas.schumacher@pdx.edu \\ Avinash Unnikrishnan \\ Portland State University, uavinash@pdx.edu
}

Follow this and additional works at: https://pdxscholar.library.pdx.edu/cengin_fac

Part of the Transportation Engineering Commons

Let us know how access to this document benefits you.

\begin{abstract}
Citation Details
Ghonima, O., Anderson, J. C., Schumacher, T., \& Unnikrishnan, A. (2020). Performance of US Concrete Highway Bridge Decks Characterized by Random Parameters Binary Logistic Regression. ASCE-ASME Journal of Risk and Uncertainty in Engineering Systems, Part A: Civil Engineering, 6(1), 04019025.
\end{abstract}

This Pre-Print is brought to you for free and open access. It has been accepted for inclusion in Civil and Environmental Engineering Faculty Publications and Presentations by an authorized administrator of PDXScholar. Please contact us if we can make this document more accessible: pdxscholar@pdx.edu. 
$6{ }^{1}$ Pricing Lead, Careem, Media City, Al Shatha Tower, 40th floor, 4005, Dubai, U.A.E. E-mail:

$7 \quad$ omar.ghonima@careem.com

$8{ }^{2}$ Post-Doctoral Research Associate, Civil and Environmental Engineering, Portland State

9 University, 1930 SW 4th Avenue, Suite 200, Portland, OR, 97201, USA. E-mail:

$10 \quad$ jason.c.anderson@pdx.edu

$11{ }^{3}$ Associate Professor, Civil and Environmental Engineering, Portland State University, 1930

12 SW 4th Avenue, Suite 200, Portland, OR, 97201, USA. E-mail: thomas.schumacher@pdx.edu

$13{ }^{4}$ Associate Professor, Civil and Environmental Engineering, Portland State University, 1930

14 SW 4th Avenue, Suite 200, Portland, OR, 97201, USA. E-mail: unavinash@pdx.edu

15

$16 *$ Corresponding author

\section{ABSTRACT}

19 This study employs a random parameters binary logistic regression (LR) to characterize the impact

20 of environmental and structural parameters on concrete highway bridge deck deterioration

21 nationwide. Two specific gaps in the literature are addressed: the use of a nationwide dataset for

22 analysis and the implementation of a methodology to account for unobserved heterogeneity. A

23 total of 3,262 bridge deck deterioration observations derived from the authors' Nationwide 
24 Concrete Highway Bridge Deck Performance Inventory (NCBDPI) database were used in this

25 study. Deterioration rate (DR) was computed as the decrease in the concrete bridge deck condition

26 rating (CR) over time. Bridge decks with deterioration rates (DR) below a certain threshold were

27 categorized as the lowest deteriorated bridge decks ("lowest DR") and decks with DR above a

28 certain threshold were considered among the highest deteriorated ("highest DR"). The following

29 variables were found to be significant in the final model: average daily truck traffic (ADTT),

30 climatic region, distance from seawater, bridge deck area, age of bridge, type of design and/or

31 construction, structural material design, deck protection, type of membrane, type of wearing

32 surface, and maintenance responsibility. The results show that bridge decks with a high ADTT,

33 age of bridge, bridge decks located in cold regions, and those that are close to seawater are

34 associated with the "highest DR" group of bridge decks. Furthermore, type of design and/or

35 construction and maintenance responsibility play a role in deck being associated with "highest 36 DR”.

38 Keywords: Highway bridge deck, concrete, performance, deterioration, National Bridge 39 Inventory, database, random parameters binary logistic regression.

\section{INTRODUCTION AND BACKGROUND}

42 Over 600,000 bridges across all states represent critical components of the US transportation 43 system, ensuring network continuity. The highest costs in bridge superstructure repair and 44 rehabilitation are incurred through maintenance, repair, and replacement of concrete bridge decks 45 (Li and Zhang, 2001). Understanding the causes of bridge deck deterioration is therefore central 46 to asset management. Bridge decks, which are exposed to freeze and thaw cycles, deicers, and 
47 heavy traffic loads, are a bridge's most susceptible element. Concrete bridge deck deterioration is

48 also a leading cause for structural deficiency (Russell 2004). According to the Federal Highway

49 Administration (FHWA), two billion dollars are spent annually for maintenance and capital costs

50 for concrete bridge decks (ASCE, 2013). As a direct consequence, Departments of Transportation

51 (DOT) and the FHWA are interested to determine the reasons behind concrete bridge deck

52 deterioration.

54 Previous work has attempted to model bridge condition ratings (CR) by using various deterministic

55 and stochastic models, such as simple regression (Morcous and Hatami, 2011), multiple regression

56 (Reardon, 2015, Tae-Hoon et al., 2006; Bolukbasi et al., 2004), Markov models (Agrawal et al.,

57 2010; Morcous, 2006, Madanat, 1995), and Bayesian models (Attoh-Okine and Bowers, 2006).

58 Although these methods have been used to model bridge CR, the most commonly used and widely

59 accepted method across civil engineering disciplines is logistic regression (LR). In the

60 transportation field, LR has been widely used to model injury severity of crashes (Dissanayake

61 and Lu, 2002; Harb et al., 2008; Donnell and Mason, 2004; Al-Ghamdi, 2002; Mannering and

62 Bhat, 2014; Anderson and Hernandez, 2017; Al-Bdairi et al., 2018) and route/mode choice (Abdel-

63 Aty and Abdalla 2004; Bierlaire et al. 2010; Dalumpines and Scott 2017; Mai et al. 2015; Mishra

64 et al. 2013; Tan et al. 2015; Vidana-Bencomo et al. 2018; Washington et al. 2009). In construction

65 management, LR has been used to model contractors' bids and worker safety (Lowe and Parvar,

66 2004; Hwang and Kim, 2016; Alomari et al., 2017), disputes (Diekmann and Girard, 1995; Cheung

67 et al., 2010), contractors performance (Wong, 2004), and risk analysis (Ozdemir, 2016; Mwesige

68 et al., 2016; Smith and McCarty, 2009). Lastly, in structural engineering, LR models have been

69 used to study the performance of beam-column connections (Mitra et al., 2011; Kang and Mitra, 
2012) and failure mode of reinforced concrete interior beam column joints under seismic loading

71 (Vandana and Bindhu 2017).

73 More closely related to this study, Ariaratnam et al. (2001) used LR to study the performance of

74 local sewer systems in Edmonton, Canada. Age, diameter, material, waste type, and average depth

75 of cover were modeled as the independent variable. Salman and Salem (2012) applied three

76 different regression models, including multinomial and binary logistic regression to establish

77 deterioration models for wastewater collection lines. Shan and Lewis (2016) used a binary LR to

78 characterize deficient steel bridges with concrete cast-in-place deck and multibeam/girder designs

79 based on the NBI data. The best model consisted of eight independent variables (average daily

80 traffic (ADT), structure length, length of maximum span, bridge roadway width, state code, owner,

81 and age), two of which, owner and state code, were insignificant. In addition to these studies, there

82 have been recent works that use LR to study material behavior. This has included evaluating the

83 splitting tensile strength in plain and steel fiber-reinforced concrete based on compressive strength

84 (Behnood et al. 2015), reproducing the stiffness degradation curve of asphalt specimens during

85 fatigue testing (Mateos et al. 2017), analysis of asphalt fatigue test results (Mateos et al. 2015),

86 and comparing low-temperature crack intensity on pavements with high modulus asphalt concrete

87 and conventional asphalt concrete (Rys et al. 2017).

88

89 Directly related to the current study, statistical analysis and modeling of concrete bridge deck

90 condition data has been performed by several researchers. For example, Madanat, et al. (1995)

91 used an ordered probit model to estimate Markovian transition probabilities from deck condition

92 ratings contained in the Indiana Bridge Inventory (IBI), a subset of the NBI. Using the same data 
93 set, Mauch and Madanat (2001) introduced a semiparametric hazard rate model and stochastic

94 duration models (Mishalani and Madanat, 2002) to study bridge deck condition transition

95 probabilities. Using NBI data for the State of Wisconsin, Tabatabai, et al. (2011) evaluated

96 different distributions for analysis of condition rating data. More, a number of published studies

97 have specifically investigated the effects of chloride penetration on deck performance (e.g.,

98 Williamson, 2007; Lounis, 2000; Wedding et al., 1983).

99

100 While some published work has focused on concrete bridge deck CR, no attempts have been made

101 to use a nationwide dataset. Some studies have used subsets of a nationwide dataset, but focus on

102 a disaggregated picture (i.e., state or region). In addition, since these works have been completed,

103 the NBI dataset has substantially grown and provides researchers with more information for

104 analysis. A nationwide model can provide a holistic view of variables that impact bride deck

105 deterioration. More, using region-specific indicators (i.e., climatic characteristics), the nationwide

106 model can potentially help in identifying problematic regions regarding bridge deck deterioration.

107 This, in turn, can lead to more focused analyses based on needs, as well as define regions based

108 on such characteristics. As it pertains to structural and bridge engineering applications, as well as

109 applications to concrete bridge decks, the LR analyses do not address what has become a prevalent

110 issue in today's datasets: unobserved heterogeneity (i.e., unobservables). As such, the current study

111 distinctively fills these gaps in the literature. To the best of the authors' knowledge, this is the first

112 attempt at modeling NBI data on a nationwide scale and the first attempt at overcoming a key

113 limitation within the NBI data by utilizing a random parameters estimation approach to account

114 for unobserved heterogeneity. 


\section{Objective and Motivation}

117 The objective of this study was to characterize the effect of various environmental, structural,

118 construction, climatic, and traffic related parameters on concrete bridge deck performance.

119 Specifically, the focus was on two extreme groups: bridges that have experienced the highest and

120 lowest levels of deterioration. A random parameters binary LR framework was developed to

121 quantify the impact of various parameters on the likelihood of a bridge deck being associated with

122 the group of highest and lowest deterioration rates (DR), while also accounting for a key limitation

123 within the data: unobserved heterogeneity. This method uniquely fills a gap in literature with its

124 application to bridge deck deterioration.

126 DATASET

127 The authors have created a Nationwide Concrete Bridge Deck Performance Inventory (NCBDPI) 128 database (Ghonima et al., 2018) with the specific goal of adopting a more statistical and data 129 mining approach to understanding concrete highway bridge deck performance. The primary source 130 of information for the NCBDPI database is the National Bridge Inventory (NBI) database (FHWA, 131 2017). For this research, a number of NBI items were extracted and complemented with additional 132 parameters such as climatic region, distance to seawater, bridge age, and deterioration rate (DR).

133 One of the key performance metrics available in the authors' NCBDPI database is the DR, which 134 is defined as follows (Ghonima et al., 2018):

135

$$
\mathrm{DR}=\left(\mathrm{CR}^{\prime}-\mathrm{CR}^{\prime \prime}\right) / \mathrm{TICR}
$$


138 where CR' and CR" are the bridge deck condition ratings (CR) at the beginning and end of a series

139 of consecutive CR, and TICR (= time-in-condition rating) is the duration in years, as illustrated in

140 Fig. 1. Deterioration is referred to as the observed decrease in CR. Also, maintenance is used to 141 refer to any deck improvement action that increases the CR, similar to many published materials 142 in the past. Note that the DR could only be calculated when CR' > CR', i.e. when deterioration 143 occurred. For the sample deck shown in Fig. 1, one fully observable cycle of deterioration occurs. 144 DR was employed in this analysis as the independent variable because of its ability to capture the 145 rate of change of CR, which TICR cannot. This emerged from discussions with a number of 146 stakeholders involved in the overall research (Ghonima et al., 2018), in particular from bridge 147 inspectors that have found some bridge decks to deteriorate much faster than others.

148

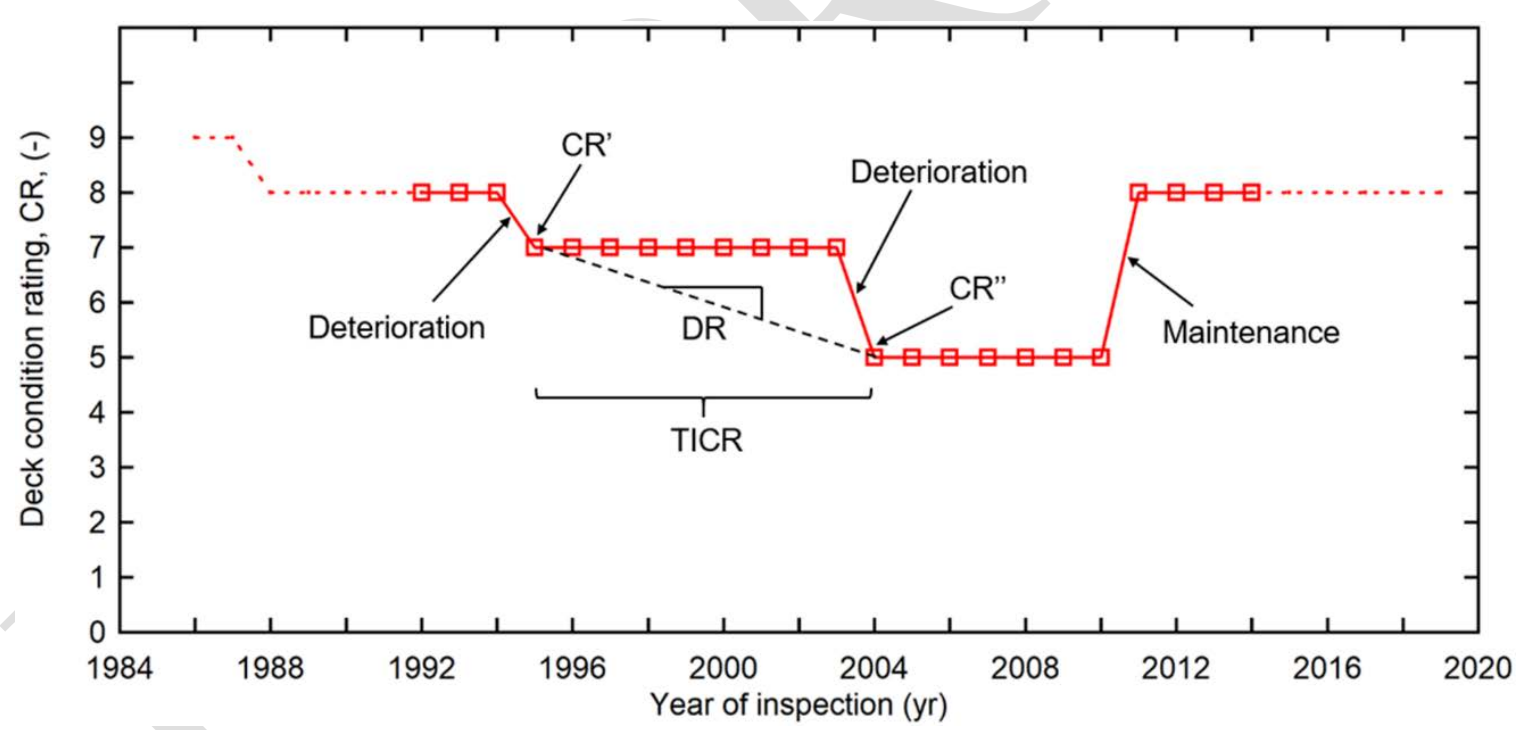

150 Fig. 1. Sample concrete bridge deck condition rating (CR) with computed independent variables. Note: A decrease and an increase in the assigned CR is considered deterioration and maintenance, respectively. Data considered in this analysis include years 1992 to 2014. 
154 This study regarded concrete bridge decks with $\mathrm{DR} \leq 0.056$ as the group with the lowest 155 deterioration rate ("lowest DR") with a total of 1,569 observations. $\mathrm{DR}=0.056$ means that a bridge

156 deck was assigned the same CR for approximately 18 years, i.e. TICR $=18$, before experiencing

157 a one-unit CR decrease. Concrete bridge decks assigned a DR $\geq 2$ were considered as part of the

158 group associated with the highest deterioration rate ("highest DR") with a total of 1,693

159 observations. DR $=2$ means that the bridge was assigned the same $\mathrm{CR}$ for one year, i.e. $\mathrm{TICR}=1$,

160 before a two-unit CR decrease occurred. The thresholds of 0.056 and 2 were selected after careful

161 analysis and discussing with practitioners, bridge engineers from two state DOTs, and the FHWA

162 what might be a reasonable TICR before a bridge deck is assigned a lower CR. While ideally, a

163 physics-based classification would be applied to select boundaries, this is not possible here given

164 that the CR are based on qualitative visual inspection results that include a number of deterioration

165 mechanisms. As can be observed, using this approach produced two groups with similar numbers

166 of samples.

167

168 The lowest and highest DR groups were coded as binary variables and assigned 0 and 1 ,

169 respectively. The reason behind taking these values was to make a clear distinction between the

170 best and worst performing concrete bridge decks.

171

172 Table 1 presents a summary of the variables included in the study and/or their frequencies. Refer

173 to Ghonima, et al. (2018) for more details. Following are some observations: The average ADTT

174 on the bridges in the dataset is nearly 1000. A significant majority of the bridges has cast-in-place

175 decks. In terms of structural material and/or design, close to $80 \%$ of the bridge decks are part of

176 either a simple or continuous span concrete or prestressed concrete bridge system. Close to $75 \%$ 
177 of the bridges have no deck protection and more than $75 \%$ of the bridges have no membrane. A

178 majority of the bridge decks captured in the sample were in rural areas. Finally, a state highway

179 agency was responsible for the maintenance of nearly two-thirds of the bridges.

180

181 Table 1. Summary statistics and counts for the bridge deck variables included in this study.

\begin{tabular}{|c|c|c|c|}
\hline Continuous variables & Minimum & Mean & Maximum \\
\hline Distance from Seawater $(\mathrm{km})$ & 0 & 5,655 & 16,619 \\
\hline $\begin{array}{l}\text { Deck Area }\left(\mathrm{ft}^{2}\right) \text { - computed from NBI } \\
\text { Items } 49 \text { and } 51\end{array}$ & 2370 & 74,304 & $4,080,000$ \\
\hline $\begin{array}{c}\text { Average Daily Truck Traffic (ADTT) - } \\
\text { NBI Item } 109\end{array}$ & 0 & 983 & 25,432 \\
\hline $\begin{array}{c}\text { Bridge Age (years) - computed from NBI } \\
\text { Items } 27 \text { or } 106 \\
\end{array}$ & 0 & 39.8 & 122 \\
\hline Number of Lanes (-) - NBI Item 28 & 1 & 1.45 & 11 \\
\hline Categorical variables & Categories & Frequency & Percentage \\
\hline \multirow{2}{*}{ Deck Structure Type - NBI Item 107} & Cast-in-Place & 2,899 & 88.0 \\
\hline & Concrete Precast Panels & 397 & 12.0 \\
\hline \multirow{6}{*}{ Structural Material/Design - NBI Item 43a } & Concrete - simple span & 764 & 23.2 \\
\hline & Concrete - continuous & 454 & 13.8 \\
\hline & Prestressed concrete - simple & 872 & 26.5 \\
\hline & Prestressed concrete - continuous & 515 & 15.6 \\
\hline & Steel - simple span & 554 & 16.8 \\
\hline & Steel - continuous & 137 & 4.2 \\
\hline \multirow{8}{*}{ Climatic Region (IECC) } & Very Hot & 215 & 6.5 \\
\hline & Hot & 919 & 27.9 \\
\hline & Average & 553 & 16.8 \\
\hline & Cold & 1,045 & 31.7 \\
\hline & Very Cold (VC) & 444 & 13.5 \\
\hline & Extremely Cold (EC) & 33 & 1.0 \\
\hline & Average Marine (AM) & 38 & 1.2 \\
\hline & Hot Marine (HM) & 49 & 1.5 \\
\hline \multirow{9}{*}{ Deck Protection - NBI Item 108c } & None & 2,421 & 73.5 \\
\hline & Epoxy-Coated Reinforcing & 487 & 14.8 \\
\hline & Galvanized Reinforcing & 16 & 0.5 \\
\hline & Other Coated Reinforcing & 4 & 0.1 \\
\hline & Cathodic Protection & 2 & 0.1 \\
\hline & Polymer Impregnated & 11 & 0.3 \\
\hline & Internally Sealed & 1 & 0.0 \\
\hline & Unknown & 329 & 10.0 \\
\hline & Other & 25 & 0.8 \\
\hline \multirow{6}{*}{ Type of Membrane - NBI Item 108b } & None & 2,566 & 77.9 \\
\hline & Built-up & 106 & 3.2 \\
\hline & Preformed Fabric & 99 & 3.0 \\
\hline & Epoxy & 23 & 0.7 \\
\hline & Unknown & 403 & 12.2 \\
\hline & Other & 99 & 3.0 \\
\hline
\end{tabular}


Table 1. (Continued)

\begin{tabular}{|c|c|c|c|}
\hline \multirow{9}{*}{ Type of Wearing Surface - NBI Item 108a } & None & 207 & 6.3 \\
\hline & Monolithic Concrete & 1,239 & 37.6 \\
\hline & Integral Concrete & 248 & 7.5 \\
\hline & $\begin{array}{l}\text { Latex Concrete or Similar } \\
\text { Additive }\end{array}$ & 131 & 4.0 \\
\hline & Low-Slump Concrete & 59 & 1.8 \\
\hline & Epoxy Overlay & 36 & 1.1 \\
\hline & Bituminous & 1,160 & 35.2 \\
\hline & Timber & 88 & 2.7 \\
\hline & Other & 128 & 3.9 \\
\hline \multirow{2}{*}{$\begin{array}{c}\text { Functional Classification of Inventory } \\
\text { Route - NBI Item } 26 \\
\end{array}$} & Rural & 2,339 & 71.0 \\
\hline & Urban & 957 & 29.0 \\
\hline \multirow{10}{*}{$\begin{array}{c}\text { Type of Design and/or Construction - NBI } \\
\text { Item 43b }\end{array}$} & Slab & 664 & 20.1 \\
\hline & Stringer/multi-beam or girder (SB) & 1,628 & 49.4 \\
\hline & Girder and floor beam system & 60 & 1.8 \\
\hline & Tee beam (TB) & 275 & 8.3 \\
\hline & $\begin{array}{l}\text { Box beam or girders - multiple } \\
(\mathrm{BBM})\end{array}$ & 387 & 11.7 \\
\hline & $\begin{array}{l}\text { Box beam or girders - single or } \\
\text { spread (BBS) }\end{array}$ & 36 & 1.1 \\
\hline & Frame & 17 & 0.5 \\
\hline & Truss - through & 60 & 1.8 \\
\hline & Arch-deck & 17 & 0.5 \\
\hline & Channel beam (CB) & 152 & 4.6 \\
\hline \multirow{5}{*}{ Maintenance Responsibility - NBI Item 21} & State Highway Agency & 2,134 & 64.7 \\
\hline & County Highway Agency (CHA) & 838 & 25.4 \\
\hline & $\begin{array}{l}\text { Town or Township Highway } \\
\text { Agency }\end{array}$ & 139 & 4.2 \\
\hline & $\begin{array}{l}\text { City of Municipal Highway } \\
\text { Agency (CMHA) }\end{array}$ & 140 & 4.2 \\
\hline & State Toll Authority (STA) & 45 & 1.4 \\
\hline
\end{tabular}

185 ANALYSIS

186 Logistic Regression

187 Logistic (or logit) regression (LR), a modeling approach that describes the occurrence probability

188 of an outcome or event, is a method of fitting a regression curve to determine the outcome 189 probability of said outcome or event as a function of covariates (i.e., independent variables). In the 190 case of binary logistic regression, in which the outcomes are binary (i.e., 0 or 1 ), the probability 191 that the outcome takes on the value 1 is determined through a set, or function, of covariates (Train 192 2009; Washington et al. 2011; Greene 2018). Covariates can be continuous, categorical, or both. 
193 For the current study, the outcome being modeled is bridge deck deterioration rate (DR), where 194 concrete bridge decks associated with the two groups "lowest DR" and "highest DR" were coded 195 as 0 and 1 , respectively. Because some of the independent variables are categorical, several 196 indicator variables were created to differentiate the different categories. But, to avoid 197 multicollinearity issues, only $k$-1 indicators from the same categorical variable could be included 198 in the final model specifications (Yannis, et al., 2011). For example, the variable category Climatic 199 Region (Table 1) consists of 8 different sub-categories; therefore, at most, seven indicator variables 200 indicating climatic region can be included in final model specifications.

201

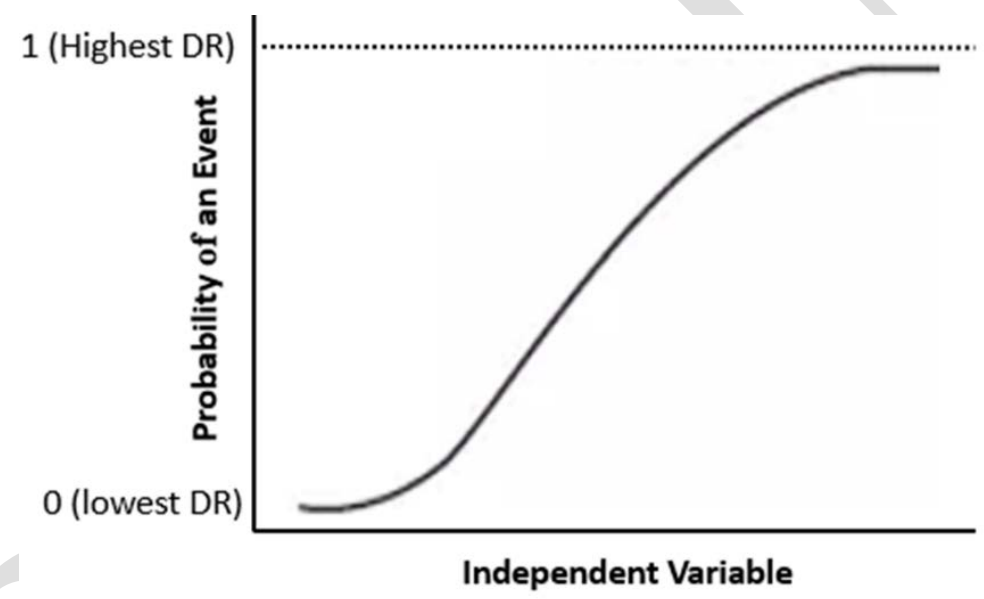
Fig. 2. S-shape probability function used in binary logistic regression (LR).

205 The probability function of a logit model that describes a dependent variable in terms of 206 independent variables can be represented as an S-shape function (Fig. 2), where the logit 207 probability is represented as (McFadden 1981; Train 2009):

208

$$
P_{n}(i)=\frac{e^{\left(\beta_{i} X_{i n}\right)}}{\sum_{\forall i} e^{\left(\beta_{i} X_{i n}\right)}}
$$


209 where $P_{n}(i)$ is the probability of observation $n$ having outcome $i, \beta_{i}$ is a vector of estimable

210 parameters indexed by outcome $i$, and $X_{i n}$ is a vector of explanatory variables (e.g., climatic

211 region, wearing surface, etc.) used to determine the outcome probability. Now, by satisfying the

212 alternative-specific-constant rule in logit modeling (see Train (2009) for a full discussion),

213 normalizing one of the outcomes to utilize a binary logit framework for the current study results

214 in the following (Train 2009; Washington et al. 2011; Hensher et al. 2015; Greene 2018):

215

$$
P_{n}(i)=\frac{e^{(\widehat{\beta})}}{1+e^{(\widehat{\beta})}}, \text { where } \hat{\beta}=\beta_{0}+\beta_{1} X_{1, n}+\cdots+\beta_{i} X_{i, n}+\varepsilon_{i n}
$$

217 where $\varepsilon_{i n}$ is a Type I Extreme Value distributed error term and all other terms have been defined

218 previously. The error term attempts to capture unobservables within the data; that is, attributes that

219 are unobserved by the analyst (variables not included or collected in the data). In the case of the

220 current study, each and every variable that contributes to the deterioration of a bridge deck is likely

221 not included in the utilized data. This could be a result of several factors, such as the data is

222 unavailable or the data is not collected. Therefore, these variables not included in the data are

223 considered unobservables. These unobservables can result in unobserved heterogeneity, which if

224 not accounted for, can result in biased estimates, incorrect inferences, and inaccurate

225 recommendations. In addition, unobserved heterogeneity can be a result of variation within an

226 existing variable due to unobserved characteristics. For instance, climatic regions are available,

227 but no information on weather irregularities are included. This unobservable can be "embedded"

228 in climatic region variables; therefore, resulting in unobserved heterogeneity (the reader is referred

229 to Mannering et al. (2016) for a full discussion on methods and implications as it pertains to

230 unobserved heterogeneity in econometric analyses). 
231 As such, the current study attempts to account for these unobservables by estimating a model with

232 random parameters. As opposed to a traditional logit model, in which coefficient estimates are

233 assumed to have the same sign (or effect) across all observations, a random parameters model

234 allows beta estimates to vary across observations based on a distribution defined by the analyst

235 (i.e., beta will be negative for a proportion of observations and positive for the remainder, or vice-

236 versa). To estimate such a model, a mixing distribution is introduced to the binary logit formulation

237 in Eq. (2) (Greene 2016a; McFadden and Train 2000; Train 2003; Washington et al. 2011):

238

$$
P_{n}(i \mid \phi)=\int_{x} \frac{e^{(\widehat{\beta})}}{1+e^{(\widehat{\beta})}} f(\hat{\beta} \mid \phi) d \hat{\beta}
$$

240 where $P_{n}(i \mid \phi)$ is now the weighted outcome probability of $P_{n}(i)$ taking on the value 1 conditional

241 on $f(\hat{\beta} \mid \phi)$. In particular, $f(\hat{\beta} \mid \phi)$ is the density function of $\hat{\beta}$ with distributional parameter $\phi$.

242 The density function, $f(\hat{\beta} \mid \phi)$, is what allows parameter estimates to vary across observations so

243 as to permit $\hat{\beta}$ to account for observation-specific variations of the effect of $X$ on $P_{n}(i \mid \phi)$

244 (Washington et al. 2011). In general, the density function is specified to be normally distributed

245 and is the distribution assigned to $f(\hat{\beta} \mid \phi)$ in the present study (Greene 2016b; Hensher et al. 246 2015).

248 Due to difficulties in computing the probabilities in such a model, a simulation-based approach is 249 applied to estimate parameters. To simulate, previous work has shown that Halton draws provide 250 a preferred alternative to merely random draws; therefore, Halton draws are used in the current 251 study (Bhat 2003; Halton 1960; Train 2000). Using Halton draws, the simulated probabilities are 
252 inserted into the log-likelihood function of the logit model, thus providing a simulated log-

253 likelihood (Train 2009; Washington et al. 2011):

254

$$
S L L=\sum_{n=1}^{N} \sum_{i=1}^{I} \delta_{i n} \ln \left[P_{n}(i \mid \phi)\right]
$$

255

256 where $N$ is the total number of observations, $I$ is the total number of outcomes, $\delta_{\text {in }}$ is equal to 1 if

257 the observed outcome for observation $n$ is $i$ and zero otherwise, and all other terms have been 258 defined previously. Using Halton draws, $P_{n}(i \mid \phi)$ are approximated by drawing values of $\beta$ from 259 the density function (given values of the distribution parameter $\phi$ ) and used to estimate the logit 260 probability shown in Eq. (2). This is done many times and the computed logit probabilities are 261 then summed and averaged to obtained the simulated probability, $P_{n}(i \mid \phi)$.

262

263 LR differs from multiple linear regression with respect to the interpretation of the coefficients of 264 the independent variables. In multiple linear regression, the beta estimates can be interpreted as a 265 marginal effect (i.e., the effect on a dependent variable due to a one-unit increase in explanatory 266 variable, $X$ ). However, this is not the case with LR models. In some cases, LR coefficients are 267 interpreted using the log of the odds (i.e., odds ratios). However, odds ratios are most often seen 268 in the statistics literature (Ramsey and Schafer 2012), whereas pure econometrics analyses almost 269 exclusively consist of marginal effects to interpret parameter estimates (Greene 2018; Greene and 270 Hensher 2010; Hensher et al. 2015). Therefore, the current study uses marginal effects to interpret 271 estimates from the LR model.

272 
273 As described previously, marginal effects measure the impact of an explanatory variable, due to a

274 one-unit increase, on the probability that the outcome takes on the value 1 . For continuous

275 explanatory variables, marginal effects are computed as (Greene 2016a, 2018):

276

$$
\frac{\partial P_{n}(i)}{\partial X_{\text {ink }}}=\left[1-P_{n}(i)\right] P_{n}(i) \beta_{n(i)}
$$

278 where $\frac{\partial P_{n}(i)}{\partial X_{i n k}}$ is the derivative of the probability of observation $n$ having deterioration outcome $i$.

279 However, for indicator variables, marginal effects are computed differently. For indicator variables

280 (the majority of variables used in the present study), marginal effects are defined as the difference

281 of the estimated probabilities when indicator variable $X_{i n k}$ changes from zero to one while all other

282 variables remain equal to their means (remain constant) (Greene 2018):

283

$$
M_{X_{i n k}}^{P_{n}(i)}=\operatorname{Pr}\left[P_{n}(i)=1 \mid \mathrm{X}_{\left(X_{i n k}\right)}, X_{i n k}=1\right]-\operatorname{Pr}\left[P_{n}(i)=1 \mid \mathrm{X}_{\left(X_{i n k}\right)}, X_{i n k}=0\right]
$$

284

285 where $X_{\left(X_{i n k}\right)}$ is the mean of all other variables (the variables that are being held constant) while $286 \quad X_{\text {ink }}$ changes from zero to one.

\section{Logistic Regression Coefficients}

289 This study began by generating several indicators from the categorical variables and creating 290 natural logarithm variables from variables that had large values, as this would result in marginal 291 effects of essentially zero (marginal effects are discussed in the coming sections) (i.e., ADTT, deck 292 area, distance from seawater, etc.). Using a stepwise procedure, in which the model was built-up 
293 from just the constant, Table 2 shows that 25 variables were found to have a statistically significant

294 impact on bridge deck deterioration. In addition, as anticipated, model estimates show that the data

295 is susceptible to large amounts of heterogeneity (i.e., unobservables). This is observed by the 9

296 variables with normally distributed estimated random parameters. That is, these 9 variables have

297 heterogeneous effects on bridge deck deterioration.

298

299

Table 2. Random parameters binary logit model specifications.

\begin{tabular}{|c|c|c|c|c|}
\hline Variable & Coefficient & $\begin{array}{l}\text { Std. } \\
\text { Error }\end{array}$ & $t$-statistic & $\begin{array}{c}\text { Marginal } \\
\text { Effects }\end{array}$ \\
\hline Constant & 4.660 & 0.686 & 6.79 & \\
\hline Natural Logarithm of Deck Area [DA] & -0.472 & 0.064 & -7.42 & -0.117 \\
\hline Natural Logarithm of ADTT [ADTT] & 0.320 & 0.025 & 12.58 & 0.079 \\
\hline Natural Logarithm of Distance to Seawater [SW] & -0.255 & 0.028 & -9.23 & -0.063 \\
\hline Age of Bridge [AGE] & -0.028 & 0.003 & -9.62 & -0.007 \\
\hline (Std. Dev. Of Normally Distributed Random Parameter) & $(0.038)$ & $(0.002)$ & $(17.89)$ & \\
\hline \multicolumn{5}{|l|}{ Structural Material Design } \\
\hline 1 if Continuous Concrete, 0 Otherwise [CONCR] & 0.545 & 0.184 & 2.97 & 0.135 \\
\hline (Std. Dev. Of Normally Distributed Random Parameter) & (3.266) & $(0.269)$ & (12.13) & \\
\hline 1 if Simple Prestressed Concrete, 0 Otherwise [SMPCR] & 1.856 & 0.164 & 11.33 & 0.459 \\
\hline $\begin{array}{l}1 \text { if Continuous Prestressed Concrete, } 0 \text { Otherwi } \\
\text { [CONPCR] }\end{array}$ & 1.045 & 0.200 & 5.23 & 0.258 \\
\hline (Std. Dev. Of Normally Distributed Random Parameter) & (3.417) & $(0.268)$ & $(12.77)$ & \\
\hline 1 if Simple Span Steel, 0 Otherwise [SMSTL] & 0.923 & 0.167 & 5.54 & 0.228 \\
\hline (Std. Dev. Of Normally Distributed Random Parameter) & $(1.357)$ & $(0.165)$ & $(8.25)$ & \\
\hline 1 if Continuous Steel, 0 Otherwise [CONSTL] & 0.525 & 0.254 & 2.07 & 0.130 \\
\hline \multicolumn{5}{|l|}{ Climatic Region } \\
\hline 1 if Very Hot, 0 Otherwise [VH] & -1.694 & 0.238 & -7.13 & -0.419 \\
\hline 1 if Average, 0 Otherwise [AVG] & -0.778 & 0.133 & -5.84 & -0.193 \\
\hline (Std. Dev. Of Normally Distributed Random Parameter) & $(0.886)$ & $(0.169)$ & $(5.23)$ & \\
\hline 1 if Extremely Cold, 0 Otherwise [EXCLD] & 4.252 & 0.571 & 7.44 & 1.052 \\
\hline 1 if Hot Marine, 0 Otherwise [HMAR] & 1.252 & 0.482 & 2.60 & 0.310 \\
\hline \multicolumn{5}{|l|}{ Deck Protection } \\
\hline 1 if Epoxy-Coated Reinforcing, 0 Otherwise [EPOX] & 2.273 & 0.254 & 8.94 & 0.563 \\
\hline (Std. Dev. Of Normally Distributed Random Parameter) & (6.187) & $(0.488)$ & $(12.67)$ & \\
\hline 1 if Polymer Impregnated, 0 Otherwise [POLY] & 3.444 & 1.213 & 2.84 & 0.852 \\
\hline
\end{tabular}




\section{Type of Membrane}

\begin{tabular}{|c|c|c|c|c|}
\hline 1 if Built-Up Membrane, 0 Otherwise [BUM] & 0.911 & 0.219 & 4.16 & 0.226 \\
\hline \multicolumn{5}{|l|}{ Type of Wearing Surface } \\
\hline 1 if No Wearing Surface, 0 Otherwise [NOSUR] & 1.735 & 0.241 & 7.18 & 0.429 \\
\hline (Std. Dev. Of Normally Distributed Random Parameter) & $(2.218)$ & $(0.345)$ & $(6.42)$ & \\
\hline 1 if Integral Concrete, 0 Otherwise [ICON] & 1.947 & 0.250 & 7.79 & 0.482 \\
\hline $\begin{array}{l}1 \text { if Latex Concrete or Similar Additive, } 0 \text { Otherwise } \\
\text { [LATEX] }\end{array}$ & 0.730 & 0.232 & 3.14 & 0.181 \\
\hline 1 if Low-Slump Concrete, 0 Otherwise [LSLMP] & 1.866 & 0.306 & 6.10 & 0.462 \\
\hline \multicolumn{5}{|l|}{ Type of Design and Construction } \\
\hline $\begin{array}{l}1 \text { if Girder and Floor Beam System, } 0 \text { Otherwise } \\
\text { [GFBS] }\end{array}$ & 2.307 & 0 & 5.62 & 0.571 \\
\hline 1 if Tee Beam, 0 Otherwise [TB] & 1.346 & 0.198 & 6.80 & 0.333 \\
\hline 1 if Truss (Through), 0 Otherwise [TRS] & 1.991 & 0.381 & 5.22 & 0.493 \\
\hline \multicolumn{5}{|l|}{ Maintenance Responsibility } \\
\hline 1 if County Highway Agency, 0 Otherwise [CNTY] & 1.089 & 0.150 & 7.26 & 0.270 \\
\hline (Std. Dev. Of Normally Distributed Random Parameter & (3.393) & $(0.215)$ & $(15.76)$ & \\
\hline $\begin{array}{l}1 \text { if City of Municipal Highway Agency, } 0 \text { Otherwise } \\
\text { [CITY] }\end{array}$ & 0.404 & 0.259 & 1.56 & 0.100 \\
\hline (Std. Dev. Of Normally Distributed Random Parameter) & $(2.183)$ & $(0.384)$ & $(5.68)$ & \\
\hline \multicolumn{5}{|l|}{ Model Statistics } \\
\hline Number of Observations & 3,262 & & & \\
\hline Log-Likelihood at Zero & $-1,953.98$ & & & \\
\hline Log-Likelihood at Conve & $-1,484.24$ & & & \\
\hline McFadden Pseudo R-Squared & 0.24 & & & \\
\hline
\end{tabular}

304 Referring to Table 2, final model specifications show that significant variables were found in the

305 following categories: Maintenance Responsibility, Type of Design and/or Construction, ADTT,

306 Climatic Region, Distance to Seawater, Deck Area, Age of Bridge, Structural Material Design,

307 Deck Protection, Type of Membrane, and Type of Wearing Surface. Those variables were chosen

308 through a stepwise procedure based on (1) their statistical significance and (2) were assumed to

309 play a role in bridge deck performance.

311 The beta estimates and independent variables from the final model specifications can now be 312 substituted into the right-hand side of Eq. 3 to give: 
$313 \log \left(\frac{P_{n}(i)}{1-P_{n}(i)}\right)=4.660-0.472 \cdot \ln (\mathrm{DA})+0.320 \cdot \ln (\mathrm{ADTT})-0.255 \cdot \ln (\mathrm{SW})-0.028 \cdot \mathrm{AGE}+$

$3140.545 \cdot \mathrm{CONCR}+1.856 \cdot \mathrm{SMPCR}+1.045 \cdot \mathrm{CONPCR}+0.923 \cdot \mathrm{SMSTL}+0.525 \cdot \mathrm{CONSTL}-$

$3151.694 \cdot \mathrm{VH}-0.778 \cdot \mathrm{AVG}+4.252 \cdot \mathrm{EXCLD}+1.252 \cdot \mathrm{HMAR}+2.273 \cdot \mathrm{EPOX}+3.444 \cdot$

316 POLY $+0.911 \cdot$ BUM $+1.735 \cdot$ NOSUR $+1.947 \cdot$ ICON $+0.730 \cdot$ LATEX $+1.866 \cdot \mathrm{LSLMP}+$

$3172.307 \cdot \mathrm{GFBS}+1.346 \cdot \mathrm{TB}+1.991 \cdot \mathrm{TRS}+1.089 \cdot \mathrm{CNTY}+0.404 \cdot \mathrm{CITY}$

319 As mentioned previously, the more common way to interpret parameter estimates in an

320 econometric analysis is to look at marginal effects (see Table 2). Taking the natural log of ADTT

321 (continuous variable) as an example, and holding all other variables equal to their means (held

322 constant), increasing the natural logarithm of ADTT by unity significantly increases the probability

323 of high bridge deck deterioration by 7.9\%. Interpretation of marginal effects on log-transformed

324 variables follows that of Haleem and Abdel-Aty (2010). While the interpretations are similar for

325 the indicator variables, they are relative to "otherwise." This indicates that inference can be made

326 relative to all other categories, or inference can be made directly on the indicator variable. A full

327 discussion of significant variables and their effects on bridge deck deterioration probability is

328 provided in the discussion of significant variables.

\section{Variable Importance}

331 To assess the relative importance of the individual predictors in the model, the absolute value of

332 the $t$-statistic for each model variable can be used to obtain variable importance. All measures of 333 importance were scaled to have a maximum value of 100. As can be seen in Fig. 3, ADTT, simple 334 prestressed concrete, age of the bridge, and distance to seawater are the most influential variables. 


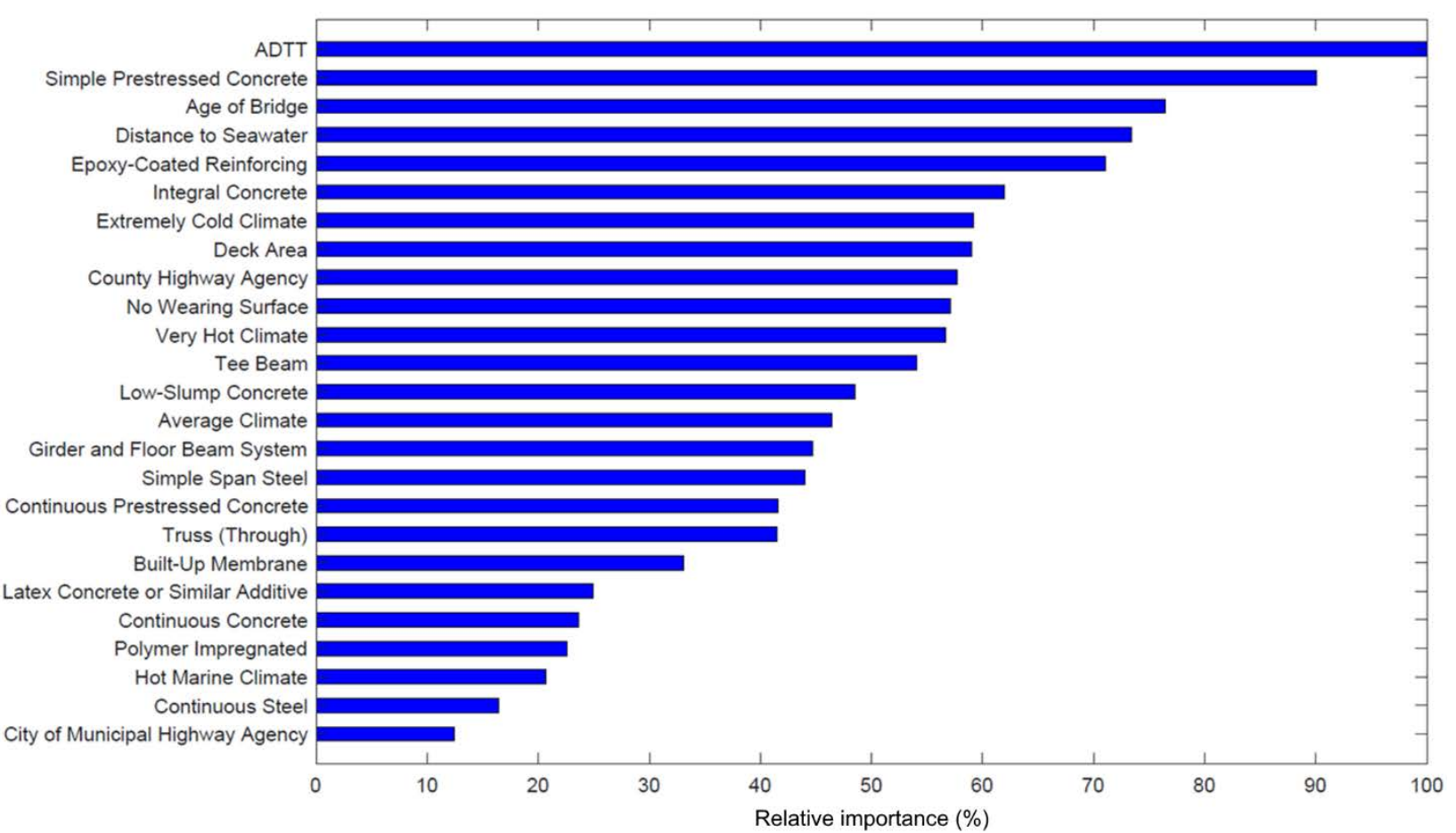

Fig. 3. Relative importance of model parameters based on $t$-statistic (scaled to 100).

\section{Variable Elasticities for Continuous Variables}

340 In addition to interpreting estimates through marginal effects, an alternate method consists of using

341 elasticities to interpret parameter estimates. In cases where the explanatory variables have large

342 values (e.g., ADTT, deck area, distance to seawater), the effect of a 1\% increase on the probability

343 of the outcome taking on the value 1 may be more intuitive (Ulfarsson and Mannering, 2004).

344 Consider a one-unit increase in ADTT to a 1\% increase in ADTT, for example. Using elasticities

345 can provide a unit-less measure to choice sensitivity to each independent variable (Yannis et al.,

346 2011; Broach, 2012). However, the calculations for elasticities is different. In NLOGIT, elasticities

347 of the probability are computed as (Greene 2016b): 


$$
\frac{\partial \log E[y \mid X]}{\partial \log X_{i n k}}=\frac{X_{i n k}}{E[y \mid X]} \times M_{X_{i n k}}^{P_{n}(i)}
$$

350 A naïve pooling method was used where elasticities for each observation were calculated and the

351 mean of all cases was taken as the elasticity (Hensher et al., 2015) (Table 3).

352

353

354

355

356

357

358

359

360

361

362

363

364

365

\section{Statistical Evaluation of the Final Model}

367 To evaluate the statistical fit of the LR model, a log-likelihood ratio test was performed. In a binary

368 LR, a model having more predictors is expected to provide a better fit to the data than a model 369 having fewer predictors. A log-likelihood ratio test estimates the overall explanatory power of a 370 model to determine if the independent variables chosen for the model improve the overall model 
371 fit. In the case of the current study, being that a model with random parameters was estimated, the

372 log-likelihood ratio test determines if the log-likelihood of the random parameters model is of

373 more significance than the log-likelihood with fixed parameters (model not accounting for data

374 unobservables). Therefore, the log-likelihood ratio test is computed as follows (Washington et al. 375 2011):

376

$$
\chi^{2}=-2\left[L L\left(\beta_{\text {Fixed }}\right)-L L\left(\beta_{\text {Random }}\right)\right]
$$

377 where $L L\left(\beta_{\text {Fixed }}\right)$ is the log-likelihood at convergence of the fixed parameters model, $L L\left(\beta_{\text {Random }}\right)$

378 is the log-likelihood at convergence of the random parameters model, and $\chi^{2}$ is a chi-square 379 statistic with degrees of freedom equal to the number of estimated random parameters in $\beta_{\text {Random }}$.

380 In the log-likelihood ratio test, the null hypothesis is that the fixed parameters model is true and 381 the alternative hypothesis is that the random parameters model is true. Thus, if the $p$-value for the 382 log-likelihood ratio test is statistically significant, there is evidence that the random parameters 383 model is preferred and the null hypothesis can be rejected (Washington et al. 2011) (Table 4).

Table 4. Likelihood ratio test results.

\begin{tabular}{|c|c|c|c|c|c|}
\hline Model & Parameters & Log-Likelihood & Degrees of Freedom & $\chi^{2}$ & $p$-value \\
\hline Fixed & 28 & $-1,953.98$ & - & - & - \\
\hline Random & 28 & $-1,484.24$ & 9 (Estimated Random & 939.48 & 0.000 \\
& & & Parameters) & & \\
\hline
\end{tabular}

387 As seen from Table 4, the null hypothesis that the fixed parameters model is preferred is rejected.

388 In particular, the overall model fit of the random parameters model is of more significance with 
well over 99\% confidence. Moreover, when comparing the log-likelihood at zero (estimated with

390 only the constant) to the log-likelihood at convergence of the random parameters model, a

391 McFadden Pseudo R-Squared value of 0.24 is obtained. A model with a McFadden Pseudo R-

392 Squared value of this magnitude is considered to have an "exceptional” fit (McFadden 1973, 1977, 393 1981).

\section{DISCUSSION OF SIGNIFICANT VARIABLES}

396 To ease discussion, a synthesis of significant variables will be done by variable category as defined

397 in Table 2. To begin, the variables not related to a specific category will be discussed (ADTT, 398 distance to seawater, and deck area have been discussed previously): age of bridge. Both of these 399 variables are significant and have heterogeneous effects (i.e., they have normally distributed 400 random parameters). As it pertains to the age of the bridge, model estimations show an estimated 401 parameter mean of -0.028 and an estimated standard deviation of 0.038 . Based on these 402 estimations, the normal distribution curve indicates that the estimated parameter mean is greater 403 than zero for $23.1 \%$ of bridge decks and less than zero for $76.9 \%$ of bridge decks. In other words, 404 as bridge age increases, $23.1 \%$ are more likely to have high deterioration and $76.9 \%$ are less likely. 405 The heterogeneous effects here may be attributed to corrosion. In regards to corrosion, it has been 406 proposed that corrosion rate decreases with age (Tabatabai and Lee 2006; Vu and Stewart 2000). 407 Therefore, as age increases, it may be less likely to observe high deterioration. However, some 408 environments are more severe than others and the natural protection from corrosion due to the high 409 alkalinity of cement-based materials can be reduced (Bien et al. 2007; Gucunski et al. 2011). For 410 the latter, this occurs due to chloride ingress, which upon reaching the rebar will destroy the 
411 passivity layer. In such a case, corrosion as a result of age can lead to an increase in likelihood of

412 high deterioration.

414 Structural Material/Design (NBI Item 43A)

415 Five variables related to structural material/design, which describes the bridge superstructure 416 material and whether it is simple-span or continuous, are found to be significant. The assumption 417 here is that when the bridge is considered continuous, so is the deck, and vice versa. Of these five 418 variables, three have heterogeneous effects on deterioration probability. The first structural 419 material/design variable with heterogeneous effects is: concrete continuous. Referring to model 420 estimations, this parameter has an estimated mean of 0.545 and an estimated standard deviation of 421 3.266. Using the normal distribution curve, these estimates indicate that $43.4 \%$ of concrete 422 continuous decks are less likely to have high deterioration and 56.7\% are more likely. Being that 423 cracking can lead to bridge deck deterioration by allowing water and chemicals to penetrate the 424 deck, this random parameter may be attempting to capture unobservables related to cracking 425 (Schmitt and Darwin 1995). Specifically, cracking is greater in continuous span decks due to the 426 negative bending moment regions at the interior supports (Grace et al. 2004). In addition, it has 427 been shown that the severity of cracking is directly correlated with the severity of vibrations 428 (Alampalli et al. 2002). Therefore, the proportion of continuous concrete bridge decks that are less 429 likely to have high deterioration may be experiencing fewer vibrations at a lesser severity, in 430 addition to less cracking (the bridges have shorter spans that result in less cracking). Also with a 431 normally distributed estimated random parameter is the indicator for continuous prestressed 432 concrete. Referring to model estimations, the estimated parameter mean of 1.045 and estimated 433 standard deviation of 3.417 indicate that $38 \%$ of bridge decks supported by a continuous 
434 prestressed concrete bridge superstructure are less likely to have high deterioration and $62 \%$ are

435 more likely. The non-homogenous nature in this variable may also be attributed to cracking. That

436 is, prestressed concrete without longitudinal cracks reduces the likelihood of deterioration due to

437 corrosion and/or freeze-thaw cycles. However, if transverse cracking takes place (i.e., parallel to

438 the transverse prestressing), there is a high likelihood of early deck deterioration, as well as

439 exposed tendons that can be prone to corrosion (Poston et al. 1989). This random parameter may

440 be capturing these differences in cracking among decks supported by prestressed concrete bridge

441 superstructures.

442

443 The third variable, also with a normally distributed random parameter, is the indicator for concrete

444 bridge decks supported by simple-span steel bridge superstructures. With an estimated parameter

445 mean of 0.923 and a standard deviation of $1.357,24.8 \%$ of bridge decks supported by simple span

446 steel bridge superstructures are less likely to experience high deterioration and $75.2 \%$ are more

447 likely to experience high deterioration relative to decks supported by simple span concrete

448 superstructures. The heterogeneous nature of this variable may be linked to end restraints of steel

449 superstructures and shrinkage (Russell 2004). In addition, concrete deck cracking is observed more

450 in curved bridges than in straight bridges and more cracking is observed as restraint increases, steel

451 configuration, girder depth, or close girder spacing (Russell 2004). These attributes impacting

452 bridge deck deterioration are unobserved in the NBI data; therefore, the randomness in this

453 parameter may be accounting for these unobservables that can result in varying effects across

454 bridge decks. 


\section{Deck Protection (NBI Item 108C)}

457 For deck protection variables, two are found to be significant. Of the two variables, the first with

458 a normally distributed random parameter is epoxy-coated reinforcing bars. Therefore, with an

459 estimated parameter mean of 2.273 and a standard deviation of $6.187,35.7 \%$ of decks protected

460 by epoxy-coated reinforcing bars are less likely to experience high deterioration and 64.3\% of

461 decks are more likely to experience high deterioration. The heterogeneous nature of this variable

462 is likely related to the location of deck deterioration. For instance, Lawler et al. (2011) found that

463 bridge decks with epoxy-coated reinforcing bars have less than $0.15 \%$ corrosion-induced

464 deterioration. However, Lawler et al. (2011) also observed deterioration in bridge decks with

465 epoxy-coated reinforcing bars, specifically at cracks or construction joints. This finding shows that

466 a large proportion of bridge decks with epoxy-coated reinforcing may have considerable

467 deterioration stemming from cracks and/or construction joints, suggesting that these locations be

468 investigated further for such bridge decks.

470 Type of Membrane (NBI Item 108B)

471 Of the several variable categories, type of membrane is the only category to have just one

472 significant variable. In particular, bridge decks with a built-up membrane have a 22.6 percentage

473 point increase in probability of suffering from high deterioration, according to marginal effects.

474 This finding may be attributed to this type of membrane being popular in the 1960s and, in nearly

475 all cases, having been discontinued (Manning 1995). For built-up membranes, two layers are used:

476 glass fabric and coats of coal-tar pitch emulsion (Hagenbuch 1971; Manning 1995). However, over

477 time, condition surveys showed that the glass fabric being used in built-up membranes was rotting

478 (Manning 1995). These findings suggest that built-up membranes increase the probability of being 
479

480

481

482

483

484

485

486

487

488

489

490

491

492

493

494 Type of Design and/or Construction (NBI Item 43B)

495 Three variables related to design and/or construction are found to significantly affect the 496 probability of high deck deterioration. For these variables, there are no heterogeneous effects 497 across bridge decks. Although, each of these variables have considerable impacts on deck 498 deterioration according to marginal effects, with one having larger effects on deck deterioration 499 compared to the others. To be specific, based on marginal effects, girder and floor beam systems 500 increase the probability of deck deterioration by 57.1 percentage points. A plausible explanation 501 for the increase in probability may be attributed to the type of bridge. For example, tied arch 
502 bridges experience web-gap fatigue in the connections of girder and floor beam systems (National

503 Academies of Sciences, Engineering, and Medicine 2013). Another plausible explanation may be

504 linked to bridges that have not been retrofitted or repaired in regards to web-gap fatigue cracks

505 (Dexter and Ocel 2013).

506

\section{Maintenance Responsibility (NBI Item 22)}

508 For this category, just two variables are found to be significant, both of which have non-

509 homogenous effects on bridge deck deterioration. The first of these variables is the indicator for

510 county highway agency (i.e., maintenance responsibility is that of a county highway agency).

511 Turning to model estimates, the indicator for county highway agency has an estimated parameter

512 mean of 1.089 and an estimated parameter standard deviation of 3.393. Based on a normal

513 distribution, these estimates indicate that $37.4 \%$ of bridge decks under the maintenance

514 responsibility of a county highway agency are less likely to have high deterioration. On the other

515 hand, however, $62.6 \%$ of bridge decks under the maintenance responsibility of a county highway

516 agency are more likely to have high deterioration. The second variable, also with a normally

517 distributed random parameter, is city or municipal highway agency being responsible for deck

518 maintenance. With an estimated parameter mean of 0.404 and an estimated standard deviation of

$5192.183,42.7 \%$ of bridge decks under the maintenance of a city or municipal highway agency are

520 less likely to have high deterioration and $57.3 \%$ of bridge decks are more likely to have high

521 deterioration. A plausible explanation for the heterogeneous nature in these two variables may be

522 linked with funding for bridge deck maintenance. For instance, routine maintenance is not eligible

523 for federal funds (FHWA 2018). Therefore, the varying effects of these two variables could be a

524 result of limited or available funding at the county-specific level or the city- and municipal-specific 
525 level. With the Highway Bridge Program giving state DOTs discretion in regards to funding bridge

526 rehabilitation, replacement, and several preservation activities (FHWA 2018), Strategic Highway

527 Research Program et al. (2018) suggest that DOTs must design and build new bridges to have the

528 longest potential service life. In doing so, this can free up funds for bridge preservation, bridge

529 maintenance, and repairs (Strategic Highway Research Program et al. 2018).

\section{IECC Climatic Region}

532 The final set of variables found to be significant on the probability of bridge deck deterioration are

533 climatic indicators. In this study, climate regions according to the International Energy

534 Conservation Code (IECC) were adopted (International Code Council 2012). Inherently, these

535 indicators serve as surrogates for region-specific climates and can help guide future work in

536 defining specific regions to be considered for region-specific bridge deterioration models. With

537 that in mind, four climatic indicators are significant, one of which has heterogeneous effects on

538 bridge deck deterioration: average climate. Referring to model estimations, the indicator for

539 average climate has an estimated parameter mean of -0.778 and an estimated standard deviation

540 of 0.886 . Therefore, based on the normal distribution curve, $19.0 \%$ of bridge decks located in the

541 average climatic region are more likely to be associated with high deterioration and $81.0 \%$ of

542 bridge decks in the average climatic region are less likely to be associated with high deterioration.

543 These varying effects may be explained by weather irregularities, such as harsh winters or extreme

544 summers. Specifically, Kesiraju (2017) found some correlation between bridge deck deterioration

545 and climate change, where climate change may be a primary source of weather irregularities

546 (Huybers et al. 2013). 
548 As for the remaining three climatic variables, very hot climates, extremely cold climates, and hot

549 marine climates impact the probability of bridge deck deterioration. First, according to marginal

550 effects, there is a 41.9 percentage point decrease in the probability of bridge deck deterioration for

551 bridge decks in very hot climates. This follows the findings of Ghonima et al. (2018), where as

552 climate becomes colder bridge decks are more likely to be associated with high deterioration, while

553 hotter climates are less likely. The next climatic variable is related to extremely cold climates.

554 Pointedly, marginal effects show that bridge decks in extremely cold climates have a 105.2

555 percentage point increase in the probability of high deterioration. This finding is in-line with

556 several previous works, as specific aspects in extremely cold climates can lead to bridge deck

557 deterioration. Bridge decks in extremely cold climates will be susceptible to a large number of

558 freeze-thaw cycles that accelerate deterioration (Hema et al. 2004). Specifically, cold climates use

559 de-icing methods, where chlorides from de-icing salts can penetrate the bridge deck and eventually

560 “depassivate” the reinforcing steel initiating corrosion (Gong et al. 2013; Njardardottir et al. 2005).

561 More, de-icers can have negative reactions with the cement paste and/or aggregates in the bridge

562 deck; therefore, increasing the likelihood of deterioration (Xie and Shi 2015). The final climatic

563 indicator is for hot marine climates, in which marginal effects show a 31.0 percentage point

564 increase in the probability of bridge deck deterioration. As it pertains to marine climates, bridge

565 decks can be exposed to sulfate ions from seawater. These sulfate ions can then attack components

566 of the cement paste in the bridge deck inducing deterioration (Hema et al. 2004). In addition,

567 marine climates have other sulfates, such as sodium and magnesium, that can also induce

568 deterioration (Hema et al. 2004).

569

570 
Table 5. Summary of significant variables and effects on deck deterioration probability.

\begin{tabular}{llc}
\hline \multicolumn{1}{c}{ Category } & \multicolumn{1}{c}{ Variable } & Effect on Probability \\
\hline Continuous Variables & Deck Area & $\downarrow$ \\
& ADTT & $\uparrow$ \\
& Distance to Seawater & $\uparrow$ \\
Structural Material Design & Age of Bridge & $\uparrow \downarrow$ \\
& Continuous Concrete & $\uparrow$ \\
& Simple Prestressed Concrete & $\uparrow \downarrow$ \\
& Continuous Prestressed Concrete & $\uparrow \downarrow$ \\
Deck Protection & Simple Span Steel & $\uparrow$ \\
& Continuous Steel & $\uparrow \downarrow$ \\
Type of Membrane & Epoxy-Coated Reinforcing & $\uparrow$ \\
Type of Wearing Surface & Polymer Impregnated & $\uparrow$ \\
& Built-Up Membrane & $\uparrow \downarrow$ \\
& No Wearing Surface & $\uparrow$ \\
& Integral Concrete & $\uparrow$ \\
Type of Design and Construction & Latex Concrete or Similar Additive & $\uparrow$ \\
& Low-Slump Concrete & $\uparrow \downarrow$ \\
& Girder and Floor Beam System & $\uparrow$ \\
Maintenance Responsibility & Tee Beam & $\uparrow$ \\
& Truss (Through) & $\uparrow \downarrow$ \\
Climatic Regions & County Highway Agency & $\uparrow \downarrow$ \\
& City or Municipal Highway Agency & $\downarrow$ \\
& Very Hot & $\uparrow \downarrow$ \\
& Average & $\uparrow$ \\
\hline & Extreme Cold & \\
& Hot Marine & \\
& &
\end{tabular}

$\downarrow=$ Decrease in Bridge Deck Deterioration Probability

$\uparrow=$ Increase in Bridge Deck Deterioration Probability

$\uparrow \downarrow=$ Heterogeneous Effects on Bridge Deck Deterioration Probability

\section{SUMMARY AND CONCLUSIONS}

573 The objective of this study was to examine how environmental and structural parameters affect the

574 performance of concrete bridge decks by means of random parameters binary logistic regression

575 (LR) modeling. The model is used to compute the likelihood for a concrete bridge deck being

576 associated with the "highest deterioration rate (DR)" group, which is the worst performing set of

577 bridge decks, while also accounting for unobservables in the data. The random parameters LR

578 model development is based on 3,262 observations extracted from a nationwide database, which 
579 was developed by the authors previously (Ghonima et al., 2018). In the final model, the DR was

580 used as the dependent variable, while ADTT, Climatic Region, Distance from Seawater, Type of

581 Design and/or Construction, Bridge Age, Bridge Deck Area, Structural Material Design, Deck

582 Protection, Type of Membrane, Type of Wearing Surface, and Maintenance Responsibility

583 characteristics were used as independent variables. A log-likelihood test was performed to show

584 that the random parameters model is preferred over the traditional binary model, where results

585 indicated with well over 99\% confidence that the random parameters model is statistically

586 preferred (several variables were found to have statistically significant random parameters).

587 Significant bridge deck deterioration variables were ranked in order of their relative importance in

588 the model. Based on marginal effects and elasticities, as presented in Table 5, it was found that

589 bridge decks 1) with higher ADTT, 2) extremely cold climate, 3) hot marine climate, and 4) with

590 no wearing surface are all associated with an increase in "highest DR" group probability. On the

591 other hand, 1) deck area, 2) distance to seawater, 3) age of bridge, and 4) very hot climates are

592 associated with a decrease in "highest DR" group probability. Some of these variables were also

593 found to be heterogeneous across observations, as detailed in the discussion.

595 In the future, additional variables could be added, such as structural design characteristics (e.g.,

596 minimum deck thickness, reinforcement bar size, bar spacing), construction practice (e.g., concrete

597 temperature, placement procedure, curing practice), specifications (e.g., water-to-cement ratio and

598 minimum cementitious material content), and other notable variables (e.g., application of deicers

599 and freeze-thaw cycles). By adding additional data (i.e., potential bridge deck deterioration

600 variables), data-heterogeneity is mitigated by reducing the number of unobservables (i.e., there are

601 more observed characteristics to be used by the analyst). In addition, it is recommended that future 
602 studies utilize this methodology to model those additional variables to determine their significance

603 and impacts on bridge deck deterioration.

604

\section{ACKNOWLEDGEMENTS}

606 The material presented in this article is based upon work supported by the Federal Highway 607 Administration under Cooperative Agreement No. DTFH61-11-H-00027. Any opinions, findings, 608 and conclusions or recommendations expressed in this publication are those of the authors and do 609 not necessarily reflect the view of the Federal Highway Administration. The authors also want to 610 thank Portland State University and the Oregon Department of Transportation for student and post611 doctoral support.

612

\section{REFERENCES}

614 Abdel-Aty, M, Abdalla, M.F., 2004. Modeling Repeated Multinomial Route Choices Under

615 Advanced Traveler Information System: Generalized Estimating Equations with Polytomous

616 Logit Function. Transportation Research Record: Journal of the Transportation Research

$617 \quad$ Board 1882, 61-69.

618 Agrawal A. K., Kawaguchi A., and Chen Z. (2010). Deterioration rates of typical bridge

619 elements in New York. Journal of Bridge Engineering, 15(4), 419-429.

620 Al-Bdairi, N.S.S., Hernandez, S., Anderson, J., 2018. Contributing Factors to Run-Off-Road

621 Crashes Involving Large Trucks under Lighted and Dark Conditions. Journal of

622 Transportation Engineering, Part A: Systems 144 (1), 1-9.

623 Al-Ghamdi, A. S. (2002). Using logistic regression to estimate the influence of accident factors

624 on accident severity. Accident Analysis and Prevention, 34, 6, 729-741. 
625 Alampalli, S., Owens, F. T., and Sandhu, D. (2002). “A Qualitative Study of Correlation between 626 Bridge Vibration and Bridge Deck Cracking.” 81st Annual Meeting of the Transportation 627 Research Board, Washington, DC.

628 Alomari, K., Gambatese, J., and Anderson, J., 2017. Opportunities for Using Building 629 Information Modeling to Improve Worker Safety Performance. Safety 3 (1), 7.

630 Anderson, J., Hernandez, S., 2017. Roadway Classifications and the Accident Injury Severities 631 of Heavy-Vehicle Drivers. Analytic Methods in Accident Research 15, 17-28.

632 Ariaratnam, S. T., El-Assaly, A., \& Yang, Y. (2001). Assessment of Infrastructure Inspection 633 Needs Using Logistic Models. Journal of Infrastructure Systems, 7, 4, 160-165.

634 ASCE (2013). Report Card for America's Infrastructure. Retrieved September 23, 2014, from 635 http://www.infrastructurereportcard.org/a/\#p/bridges/overview.

636 Attoh-Okine, N. O., \& Bowers, S. (2006). A Bayesian belief network model of bridge 637 deterioration. Proceedings of the Institution of Civil Engineers - Bridge Engineering, 159, 2, $638 \quad 69-76$.

639 Behnood, A., Verian, K.P., Modiri Gharehveran, M., 2015. Evaluation of the Splitting Tensile 640 Strength in Plain and Steel Fiber-Reinforced Concrete Based on the Compressive Strength. 641 Construction and Building Materials 98, 519-529.

642 Bhat, C.R., 2003. Simulation Estimation of Mixed Discrete Choice Models Using Randomized 643 and Scrambled Halton Sequences. Transportation Research Part B: Methodological 37 (9), $644 \quad 837-855$.

645 Bien, J., Elfgren, L., and Olofsson, J. (Eds.). (2007). Sustainable Bridges: Assessment for Future 646 Traffic Demands and Longer Lives. Dolnoslaskie Wydawnictwo Edukacyjne. 
647 Bierlaire, M., Hurtubia, R., Flötteröd, G., 2010. Analysis of Implicit Choice Set Generation

648 Using a Constrained Multinomial Logit Model. Transportation Research Record: Journal of 649 the Transportation Research Board 2175, 92-97.

650 Bolukbasi, M., Mohammadi, J., \& Arditi, D. (2004). Estimating the future condition of highway 651 bridge components using national bridge inventory data. Periodical on Structural Design and 652 Construction, 9(1), 16-25.

653 Broach, J. (2012). Discrete Choice Modeling: Theoretical Assumptions and Transportation

654 Applications. Retrieved February 28, 2017, from

655 https://drive.google.com/file/d/0B8GGT7br4AVqRWplaEhDbHlGUnM/view.

656 Cheung, S. O., Yiu, T. W., \& Chan, H. W. (2010). Exploring the Potential for Predicting Project

657 Dispute Resolution Satisfaction Using Logistic Regression. Journal of Construction

$658 \quad$ Engineering and Management, 136, 5, 508-517.

659 Dalumpines, R., Scott, D.M., 2017. Determinants of Route Choice Behavior: A Comparison of

660 Shop Versus Work Trips Using the Potential Path Area - Gateway (PPAG) Algorithm and

661 Path-Size Logit. Journal of Transport Geography 59, 59-68.

662 Dexter, R. J., and Ocel, J. M. (2013). Manual for Repair and Retrofit of Fatigue Cracks in Steel

663 Bridges. McLean, VA. Federal Highway Administration. Report No. FHWA-IF-13- 020.

664 Diekmann, J. E., \& Girard, M. J. (1995). Are Contract Disputes Predictable?. Journal of

665 Construction Engineering and Management, 121, 4, 355-363.

666 Dissanayake, S., \& Lu, J. (2002). Analysis of Severity of Young Driver Crashes: Sequential

667 Binary Logistic Regression Modeling. Transportation Research Record, 1784, 108-114. 
668

669

670

671

672

673

674

675

676

677

678

679

680

681

682

683

684

685

686

687

688

689

Donnell, E., \& Mason, J. (2004). Predicting the Severity of Median-Related Crashes in Pennsylvania by Using Logistic Regression. Transportation Research Record: Journal of the Transportation Research Board, 1897, 55-63.

FHWA. (2018). Bridge Guide Preservation: Maintaining a Resilient Infrastructure to Preserve Mobility. Washington, DC.

FHWA. (2017). National Bridge Inventory (NBI). Federal Highway Administration. Retrieved March 8, 2017, from https://www.fhwa.dot.gov/bridge/nbi.

Ghonima, O., Schumacher, T., Unnikrishnan, A., and Fleischhacker, A. (2018). Advancing Bridge Technology, Task 10: Statistical Analysis and Modeling of US Concrete Highway

Bridge Deck Performance - Internal Final Report. Portland State University Library. URL:

https://pdxscholar.library.pdx.edu/cengin_fac/443.

Gong, J., Huang, J., Wang, S., and Soltesz, S. (2013). “Potential Deicer Effects on Concrete Bridge Decks: Developing Exposure Maps.” Symposium of Climatic Effects on Pavement and Geotechnical Infrstructure, American Society of Civil Engineers, Fairbanks, AK.

Grace, N., Hanson, J. L., and AbdelMessih, H. I. (2004). “Inspection and Deterioration of Bridge Decks Constructed Using Stay-in-Place Metal Forms and Epoxy-Coated Reinforcement.” Jim L. Hanson, 11.

Greene, W.H., 2016a. LIMDEP Version 11 Econometric Modeling Guide. Plainview, NY: Econometric Software, Inc.

Greene, W.H., 2016b. NLOGIT Reference Guide. 6th ed. Plainview, NY: Econometric Software, Inc.

Greene, W.H., 2018. Econometric Analysis. 8th ed. New York, NY: Pearson. 
Greene, W.H. and Hensher, D.A., 2010. Modeling Ordered Choices. New York, NY: Cambridge

$691 \quad$ University Press.

692 Gucunski, N., Romero, F., Kruschwitz, S., Feldmann, R., and Parvardeh, H. (2011).

693 Comprehensive Bridge Deck Deterioration Mapping of Nine Bridges by Nondestructive

694 Evaluation Technologies. Ames, IA. Iowa Department of Transportation. Report No. SPR-

$695 \quad$ NDEB(90)--8H-00.

696 Hagenbuch, J. J. (1971). “Bay State Considers Alternative Bridge Deck Repairs.” Public Works, 697 102(10), 68-69.

698 Haleem, K. and Abdel-Aty, M., 2010. Examining Traffic Crash Injury Severity at Unsignalized 699 Intersections. Journal of Safety Research 41 (4), 347-357.

700 Halton, J.H., 1960. On the Efficiency of Certain Quasi-Random Sequences of Points in 701 Evaluating Multi-Dimensional Integrals. Numerishe Mathematik 2 (1), 84-90.

702 Harb, R., Yan, X., Pande, A., Radwan, E., \& Abdel-Aty, M. (2008). Freeway work-zone crash 703 analysis and risk identification using multiple and conditional logistic regression. Journal of 704 Transportation Engineering, 134, 5, 203-214.

705 Hema, J., Guthrie, W. S., and Fonseca, F. S. (2004). Concrete Bridge Deck Condition 706 Assessment and Improvement Strategies. Salt Lake City, UT. Utah Department of 707 Transportation. Report No. UT-04-16.

708 Hensher, D.A., Rose, J.M., and Greene, W.H., 2015. Applied Choice Analysis. 2nd ed. 709 Cambridge, United Kingdom: Cambridge University Press.

710 Huybers, P., Kuang, Z., and Farrell, B. (2013). “Extreme Weather and Climate Change: An 711 Interview With Harvard Climate Scientists.”Environment@Harvard, 5(1), 18-21. 
712 Hwang, J.-S., \& Kim, Y.-S. (2016). A bid decision-making model in the initial bidding phase for

713 overseas construction projects. KSCE Journal of Civil Engineering, 20, 4, 1189-1200.

714 International Code Council. (2012). International Energy Conservation Code (IECC). Retrieved

715 May 15, 2019 from: https://basc.pnnl.gov/resources/2012-iecc-international-energy-

$716 \quad$ conservation-code.

717 James, G., Witten, D., Hastie, T., \& Tibshirani, R. (2013). An Introduction to Statistical Learning

718 with Applications in R. New York: Springer.

719 Kesiraju, A. (2017). “Assessing Impact of Climate Change on Oklahoma Bridge Deck and

720 Superstructure Deterioration Uisng National Bridge Inventory Data.” University of

$721 \quad$ Oklahoma.

722 Lawler, J. S., Krauss, P. D., Kurth, J., and McDonald, D. (2011). “Condition Survey of Older

723 West Virginia Bridge Decks Constructed with Epoxy-Coated Reinforcing Bars.”

724 Transportation Research Record: Journal of the Transportation Research Board, 2220, 57-

$725 \quad 65$.

726 Li, V.C., and Zhang, L. (2001). Approaches to Enhancing Concrete Bridge Deck Durability.

727 Long Term Durability of Structural Materials, P. J. M. Monteiro, K. P. Chong, J. Larsen-

728 Basse, K. Komvopoulos, Eds., Elsevier, Berkeley, CA, 11-22.

729 Lowe, D. J., \& Parvar, J. (2004). A logistic regression approach to modelling the contractor's

730 decision to bid. Construction Management \& Economics, 22, 6, 643-653.

731 Madanat, S., Mishalani, R., Wan Hashim Wan, I. (1995). Estimation of Infrastructure Transition

732 Probabilities from Condition Rating Data. ASCE Journal of Infrastructure Systems, 1(2),

$733 \quad 120-125$. 
734 Mai, T., Fosgerau, M., Frejinger, E., 2015. A Nested Recursive Logit Model for Route Choice 735 Analysis. Transportation Research Part B: Methodological 75, 100-112.

736 Mannering, F.L., Bhat, C.R., 2014. Analytic Methods in Accident Research: Methodological

$737 \quad$ Frontier and Future Directions. Analytic Methods in Accident Research 1, 1-22.

738 Mannering, F.L., Shankar, V., and Bhat, C.R., 2016. Unobserved Heterogeneity and the

739 Statistical Analysis of Highway Accident Data. Analytic Methods in Accident Research 11, $740 \quad 1-16$.

741 Mateos, A., Gómez, J.A., Hernández, R., Tan, Y., Loría Salazar, L.G., Vargas-Nordcbeck, A.,

742 2015. Application of the Logit Model for the Analysis of Asphalt Fatigue Tests Results.

743 Construction and Building Materials 82, 53-60.

744 Mateos, A., Wu, R., Harvey, J., Denneman, E., Fan, A., 2017. The Logit Model and the Need to

745 Reproduce the Stiffness Degradation Curve of Asphalt Specimens During Fatigue Testing.

$746 \quad$ Transportation Research Record 2631.

747 Mauch, M. and Madanat, S. (2001). Semiparametric Hazard Rate Models of Reinforced

748 Concrete Bridge Deck Deterioration. ASCE Journal of Infrastructure Systems, 7(2), 49-57.

749 McFadden, D., 1973. Conditional Logit Analysis of Qualitative Choice Behavior. In: Frontiers in

$750 \quad$ Econometrics. 105-142.

751 McFadden, D., 1977. Quantitative Methods for Analyzing Travel Behaviour of Individuals:

752 Some Recent Developments. Institute of Transportation Studies. University of California.

753 McFadden, D., 1981. Econometric Models of Probabilistic Choice. In: C.F. Manksi and D.

754 McFadden, eds. Structural Analysis of Discrete Data with Econometric Applications.

755 Cambridge, MA: MIT Press, 198-269. 
McFadden, D. and Train, K., 2000. Mixed MNL Models for Discrete Response. Journal of Applied Econometrics, 15(5), 447-470.

Mishalani, R G., and Madanat, S. (2002) Computation of Infrastructure Transition Probabilities Using Stochastic Duration Models. ASCE Journal of Infrastructure Systems, 8(4), 139-148.

Mishra, S., Zhu, X., Ducca, F., 2013. An Integrated Framework for Modeling Freight Mode and Route Choice [online]. Available from: http://www.roads.maryland.gov/OPR_Research/MD13-SP209B4F_An-Integrated-Framework-for-Modeling-Freight-Mode-and-RouteChoice_Report.pdf.

Mitra, N., Mitra, S., and Lowes, L. N. (2011). Probabilistic model for failure initiation of reinforced concrete interior beam-column connections subjected to seismic loading. Engineering Structures, 33, 1, 154-162.

Morcous, G. and Hatami, A. (2011). Developing deterioration models for Nebraska bridges. Final Report. Lincoln, Neb: University of Nebraska-Lincoln.

Morcous, G. (2006). Performance Prediction of Bridge Deck Systems Using Markov Chains. Journal of Performance of Constructed Facilities, 20, 2, 146-155.

Mitra, N., Mitra, S., \& Lowes, L. N. (2011). Probabilistic model for failure initiation of reinforced concrete interior beam-column connections subjected to seismic loading. Engineering Structures, 33, 1, 154-162.

Mwesige, G., Farah, H., \& Koutsopoulos, H. N. (2016). Risk appraisal of passing zones on twolane rural highways and policy applications. Accident Analysis and Prevention, 90, 1-12.

National Academies of Sciences, Engineering, and Medicine. (2013). Design Guide for Bridges for Service Life. The National Academies Press, Washington, DC. 
779 Njardardottir, H., McCabe, B., and Thomas, M. D. A. (2005). "Concrete Bridge Deck 780 Deterioration Model Using Belief Networks.” Computers and Concrete, 2(6), 439-454.

781 Ozdemir, A. (2016). Sinkhole susceptibility mapping using logistic regression in Karapınar 782 (Konya, Turkey). Bulletin of Engineering Geology and the Environment, 75, 2, 681-707.

783 Poston, R. W., Breen, J. E., and Carrasquillo, R. L. (1989). “Design of Transversely Prestressed 784 Concrete Bridge Decks.” PCI Journal, 34(5), 68-109.

785 Ramsey, F.L. and Schafer, D.W., 2012. The Statistical Sleuth: A Course in Methods of Data 786 Analysis. 3rd ed. Boston, MA: Brooks Cole.

787 Reardon, M. F. (2015). Deterioration Modeling of Subordinate Elements and Element Interaction 788 for Bridge Management Systems. M.S. Thesis. University of Virginia.

789 Russell, H. G. (2004). NCHRP Synthesis 333: Concrete Bridge Deck Performance. Washington, 790 DC. Transportation Research Board of the National Academies.

791 Rys, D., Judycki, J., Pszczola, M., Jaczewski, M., Mejlun, L., 2017. Comparison of Low792 Temperature Cracks Intensity on Pavements With high Modulus Asphalt Concrete and 793 Conventional Asphalt Concrete Bases. Construction and Building Materials 147, 478-487. 794 Schmitt, T. R., and Darwin, D. (1995). Cracking in Concrete Bridge Decks. Topeka, KS. Kansas 795 Department of Transportation. Report No. KU-94-1.

796 Shan, Y., Cristian Contreras-Nieto, \& Lewis, P. (2016). Using data analytics to characterize steel 797 bridge deterioration. Construction Research Congress. San Juan, Puerto Rico. May 31-June $798 \quad 2,2016$.

799 Smith, S. K., \& McCarty, C. (2009). Fleeing the storm(s): an examination of evacuation behavior 800 during Florida’s 2004 hurricane season. Demography, 46, 1, 127-145. 
801 Strategic Highway Research Program, Federal Highway Administration, and AASHTO. (2018).

802 America's Bridges Need Repair or Replacement: SHRP2 is On the Job. Washington, DC.

803 Tabatabai, H., Tabatabai, M., and Lee, C.-W. (2011). Reliability of Bridge Decks in Wisconsin.

804 Journal of Bridge Engineering, 16(1), 53-62.

805 Tabatabai, H., and Lee, C.-W. (2006). "Simulation of Bridge Deck Deterioration Caused by

806 Corrosion.” CORROSION 2006, San Diego, CA.

807 Tae-Hoon, H., Seung-Hyun, C., Seung-Woo, H., \& Sang-Youb, L. (2006). Service Life

808 Estimation of Concrete Bridge Decks. KSCE Journal of Civil Engineering, 10,4, 233-241.

809 Tan, R., Adnan, M., Lee, D., 2015. A New Path Size Formulation in Path Size Logit for Route

810 Choice Modeling in Public Transport Networks. Transportation Research Record: Journal of

811 the Transportation Research Board 2538, 11-18.

812 Train, K., 2000. Halton Sequences for Mixed Logit. Department of Economics 1-18.

813 Train, K., 2003. Discrete Choice Methods with Simulation. Cambridge, MA: Cambridge

$814 \quad$ University Press.

815 Train, K.E., 2009. Discrete Choice Methods with Simulation. 2nd ed. New York, NY:

816 Cambridge University Press.Ulfarsson, G. F., \& Mannering, F. L. (2004). Differences in

817 male and female injury severities in sport-utility vehicle, minivan, pickup and passenger car

818 accidents. Accident Analysis and Prevention, 36, 2, 135-147.

819 Vandana, R.K., Bindhu, K.R., 2017. A New Model for Failure Mode of Reinforced Concrete

820 Interior Beam Column Joints Under Seismic Loading. Asian Journal of Civil Engineering 18

$821 \quad$ (2), 235-253. 
822 Vidana-Bencomo, J.O., Balal, E., Anderson, J.C., Hernandez, S., 2018. Modeling Route Choice

823 Criteria From Home to Major Streets: A Discrete Choice Approach. International Journal of

824 Transportation Science and Technology 7 (1), 74-88.

825 Vu, K. A. T., and Stewart, M. G. (2000). "Structural Reliability of Concrete Bridges Including

826 Improved Chloride-Induced Corrosion Models.” Structural Safety, 22(4), 313-333.

827 Washington, S., Congdon, P., Karlaftis, M.G., Mannering, F.L., 2009. Bayesian Multinomial

828 Logit: Theory and Route Choice Example. Transportation Research Record: Journal of the

829 Transportation Research Board 2136, 28-36.

830 Washington, S.P., Karlaftis, M.G., Mannering, F.L. (2011). Statistical and Econometric Methods

831 for Transportation Data Analysis. 2nd ed. Chapman and Hall/CRC. Boca Raton, FL:

832 Chapman and Hall/CRC.

833 Wedding, P. A., Cady, P. D., \& Weyers, R. E. (1983). Chloride Penetration and the Deterioration

834 of Concrete Bridge Decks. Cement, Concrete and Aggregates, 5, 2, 81.

835 Williamson, G. S. (2007). Service life modeling of Virginia bridge decks. Blacksburg, Va.:

$836 \quad$ University Libraries, Virginia Polytechnic Institute and State University.

837 Wong, C. H. (2004). Contractor Performance Prediction Model for the United Kingdom

838 Construction Contractor: Study of Logistic Regression Approach. Journal of Construction

$839 \quad$ Engineering and Management, 130, 5, 691-698.

840 Wooldridge, J.M. (2010). Econometric Analysis of Cross Section and Panel Data. 2nd ed.

841 Cambridge, MA: MIT Press.

842 Wu, N.-C. (2010). An Exploratory Data Analysis of National Bridge Inventory. MS Thesis.

843 University of Virginia. 
844 Xie, N., and Shi, X. (2015). "Life-Cycle Performance of Concrete Bridge Decks Exposed to

845 Deicer Environments: A New Risk Rating Method.” Symposium on Systematic Approaches

846 to Environmental Sustainability in Transportation, American Society of Civil Engineers,

$847 \quad$ Fairbanks, AK, 213-226.

848 Yannis, G., Laiou, A., Vardaki, S., Papadimitriou, E., Dragomanovits, A., \& Kanellaidis, G.

849 (2011). Parameters affecting seat belt use in Greece. International Journal of Injury Control

$850 \quad$ and Safety Promotion, 18, 3, 189-97.

851 